\title{
Hybrid Projection Algorithm for Two Countable Families of Hemirelatively Nonexpansive Mappings and Applications
}

\author{
Zi-Ming Wang ${ }^{1}$ and Poom Kumam ${ }^{2}$ \\ ${ }^{1}$ Department of Foundation, Shandong Yingcai University, Jinan 250104, China \\ ${ }^{2}$ Department of Mathematics, Faculty of Science, King Mongkut's University of Technology Thonburi (KMUTT), Bang Mod, \\ Thrung Khru, Bangkok 10140, Thailand
}

Correspondence should be addressed to Poom Kumam; poom.kum@kmutt.ac.th

Received 29 May 2013; Accepted 22 August 2013

Academic Editor: Davide La Torre

Copyright (C) 2013 Z.-M. Wang and P. Kumam. This is an open access article distributed under the Creative Commons Attribution License, which permits unrestricted use, distribution, and reproduction in any medium, provided the original work is properly cited.

Two countable families of hemirelatively nonexpansive mappings are considered based on a hybrid projection algorithm. Strong convergence theorems of iterative sequences are obtained in an uniformly convex and uniformly smooth Banach space. As applications, convex feasibility problems, equilibrium problems, variational inequality problems, and zeros of maximal monotone operators are studied.

\section{Introduction}

Throughout this paper, we always assume that $E$ is a real Banach space, $E^{*}$ is the dual space of $E, C$ is a nonempty closed convex subset of $E$ and $\langle\cdot, \cdot\rangle$ is the pairing between $E$, and $E^{*}$. We denote by $\mathbb{N}$ and $\mathbb{R}$ the sets of positive integers and real numbers, respectively.

Let $f: C \times C \rightarrow \mathbb{R}$ be a bifunction and $A: C \rightarrow$ $E^{*}$ a nonlinear mapping. The "so-called" generalized mixed equilibrium problem is to find $x \in C$ such that

$$
f(x, y)+\langle A x, y-x\rangle+\varphi(y)-\varphi(x) \geq 0, \quad \forall y \in C .
$$
that is,

The set of solutions to (1) is denoted by $\operatorname{GMEP}(f, A, \varphi)$,

$$
\begin{array}{r}
\operatorname{GMEP}(f, A, \varphi)=\{x \in C: f(x, y)+\langle A x, y-x\rangle \\
+\varphi(y)-\varphi(x) \geq 0, \forall y \in C\} .
\end{array}
$$

1.1. Analysis of Special Cases. (1) If $\varphi(\cdot) \equiv 0$, the problem (1) reduces to the generalized equilibrium problem, which is to find $x \in C$ such that

$$
f(x, y)+\langle A x, y-x\rangle \geq 0, \quad \forall y \in C .
$$

The set of solutions to (3) is denoted by $\operatorname{GEP}(f, A)$.
(2) If $A \equiv 0$, the problem (1) reduces to the mixed equilibrium problem, which is to find $x \in C$ such that

$$
f(x, y)+\varphi(y)-\varphi(x) \geq 0, \quad \forall y \in C .
$$

The set of solutions to (4) is denoted by $\operatorname{MEP}(f, \varphi)$.

(3) If $f(\cdot, \cdot) \equiv 0$, the problem (1) reduces to the mixed variational inequality of Browder type, which is to find $x \in C$ such that

$$
\langle A x, y-x\rangle+\varphi(y)-\varphi(x) \geq 0, \quad \forall y \in C .
$$

The set of solutions to (5) is denoted by $\operatorname{MVI}(A, \varphi, C)$.

(4) If $f(\cdot, \cdot) \equiv 0$ in (3), the problem (3) reduces to the classic variational inequality, which is to find $x \in C$ such that

$$
\langle A x, y-x\rangle \geq 0, \quad \forall y \in C,
$$

which is called the Hartmann-Stampacchia variational inequality. The set of solutions to (6) is denoted by $\operatorname{VI}(A, C)$.

(5) If $A \equiv 0$ in (3), the problem (3) reduces to the classic equilibrium problem, which is to find $x \in C$ such that

$$
f(x, y) \geq 0, \quad \forall y \in C .
$$

The set of solutions to (7) is denoted by $\operatorname{EP}(f)$. Given a mapping $T: C \rightarrow E^{*}$, let $f(x, y)=\langle T x, y-x\rangle$ for all 
$x, y \in C$. Then $p \in \operatorname{EP}(f)$ if and only if $\langle T p, y-p\rangle \geq 0$ for all $y \in C$; that is, $p$ is a solution of the variational inequality.

(6) If $f(\cdot, \cdot) \equiv 0$ in (4), the problem (4) reduces to the minimize problem, which is to find $x \in C$ such that

$$
\varphi(y)-\varphi(x) \geq 0, \quad \forall y \in C
$$

The set of solutions to (8) is denoted by $\operatorname{Argmin}(\varphi)$.

The problem (1) is very general in the sense that it includes, as special case, optimization problems, variational inequalities, minimax problems, monotone inclusion problems, saddle point problems, vector equilibrium problems, and the Nash equilibrium problem in noncooperative games. Numerous problems in physics, optimization, and economics reduce to finding a solution of some special case or the problem (1). Some solution methods have been proposed to solve the problems (1), (3)-(8) in Hilbert spaces and Banach spaces; see, for example, [1-7] and references therein.

A Banach space $E$ is said to be strictly convex if $\|(x+$ $y) / 2 \|<1$ for all $x, y \in E$ with $\|x\|=\|y\|=1$ and $x \neq y$. Let $S_{E}=\{x \in E:\|x\|=1\}$ be the unit sphere of $E$, and define $f: S_{E} \times S_{E} \times \mathbb{R} \backslash\{0\} \rightarrow \mathbb{R}$ by

$$
f(x, y, t)=\frac{\|x+t y\|-\|x\|}{t}
$$

for $x, y \in S_{E}$ and $t \in \mathbb{R} \backslash\{0\}$. A Banach space $E$ is said to be smooth if the $\operatorname{limit}_{t \rightarrow 0} f(x, y, t)$ exists for each $x, y \in S_{E}$. It is also said to be uniformly smooth if the limit $\lim _{t \rightarrow 0} f(x, y, t)$ is attained uniformly for $(x, y) \in S_{E} \times S_{E}$.

The modulus of convexity of $E$ is the function $\delta:[0,2] \rightarrow$ $[0,1]$ defined by

$$
\begin{aligned}
\delta(\varepsilon)=\inf \left\{1-\left\|\frac{x+y}{2}\right\|: x, y \in E,\right. \\
\|x\|=\|y\|=1,\|x-y\| \geq \varepsilon\} .
\end{aligned}
$$

A Banach space $E$ is uniformly convex if and only if $\delta(\varepsilon)>0$ for all $\varepsilon \in(0,2]$. Let $p$ be a fixed real number with $p \geq 2$. A Banach space $E$ is said to be $p$-uniformly convex if there exists a constant $c>0$ such that $\delta(\varepsilon) \geq c \varepsilon^{p}$ for all $\varepsilon \in[0,2]$. Observe that every $p$-uniformly convex is uniformly convex. One should note that no Banach space is $p$-uniformly convex for $1<p<2$. It is well known that $L_{p}\left(l_{p}\right)$ or $W_{m}^{p}$ is $p$ uniformly convex if $p \geq 2$ and 2 -uniformly convex if $1<$ $p \leq 2$; see [8] for more details.

For each $p>1$, the generalized duality mapping $J_{p}: E \rightarrow$ $2^{E^{*}}$ is defined by

$$
\begin{array}{r}
J_{p}(x)=\left\{x^{*} \in E^{*}:\left\langle x, x^{*}\right\rangle=\|x\|^{p},\right. \\
\left.\left\|x^{*}\right\|=\|x\|^{p-1}\right\}, \quad \forall x \in E .
\end{array}
$$

In particular, if $p=2, J_{p}$ is called the normalized duality mapping. If $E$ is a Hilbert space, then $J_{p}=I$, where $I$ is the identity mapping. In this paper, We denote by $J$ the normalized duality mapping. It is known that the duality mapping $J$ has the following properties:

(i) if $E$ is smooth, then $J$ is single valued;

(ii) if $E$ is strictly convex, then $J$ is one to one;

(iii) if $E$ is reflexive, then $J$ is surjective;

(iv) if $E$ is uniformly smooth, then $J$ is uniformly normto-norm continuous on each bounded subset of $E$;

(v) if $E^{*}$ is uniformly convex, then $J$ is uniformly continuous on bounded subsets of $E$ and $J$ is single valued and also one to one (see [9-12]).

Let $E$ be a smooth Banach space. Consider the function defined by

$$
\phi(x, y)=\|x\|^{2}-2\langle x, J y\rangle+\|y\|^{2}, \quad \forall x, y \in E .
$$

It is obvious from the definition of the function $\phi$ that

$$
(\|x\|-\|y\|)^{2} \leq \phi(x, y) \leq(\|x\|+\|y\|)^{2}, \quad \forall x, y \in E .
$$

We also know that $\phi(x, y)=0$ if and only if $x=y$ (see [13]). Moreover, if $E$ is a Hilbert space, (12) reduces to $\phi(x, y)=$ $\|x-y\|^{2}$, for any $x, y \in E$.

Let $C$ be a closed convex subset of $E$, and let $T$ be a mapping from $C$ into itself. We denote by $F(T)$ the set of fixed points of $T$. A point $p$ in $C$ is said to be an asymptotic fixed point of $T$ [14] if $C$ contains a sequence $\left\{x_{n}\right\}$ which converges weakly to $p$ such that the strong $\lim _{n \rightarrow \infty}\left(x_{n}-T x_{n}\right)=0$. The set of asymptotic fixed points of $T$ will be denoted by $\widehat{F}(T)$. A point $p$ in $C$ is said to be a strong asymptotic fixed point of $T$ [14] if $C$ contains a sequence $\left\{x_{n}\right\}$ which converges strong to $p$ such that $\lim _{n \rightarrow \infty}\left\|x_{n}-T x_{n}\right\|=0$. The set of strong asymptotic fixed points of $T$ will be denoted by $\widetilde{F}(T)$.

Let $T: C \rightarrow C$ be a mapping, and recall the following definition:

(a) $T$ is called nonexpansive if

$$
\|T x-T y\| \leq\|x-y\|, \quad \forall x, y \in C ;
$$

(b) $T$ is called relatively nonexpansive if $\widehat{F}(T)=F(T) \neq \emptyset$ and

$$
\phi(p, T x) \leq \phi(p, x), \quad \forall x \in C, p \in F(T) ;
$$

(c) a mapping $T$ is said to be weak relatively nonexpansive if $\widetilde{F}(T)=F(T) \neq \emptyset$ and

$$
\phi(p, T x) \leq \phi(p, x), \quad \forall x \in C, p \in F(T) ;
$$

(d) a mapping $T$ is called hemirelatively nonexpansive if $F(T) \neq \emptyset$ and

$$
\phi(p, T x) \leq \phi(p, x), \quad \forall x \in C, p \in F(T) .
$$

Remark 1. From the definitions, it is obvious that a relatively nonexpansive mapping is a weak relatively nonexpansive mapping, and a weak relatively nonexpansive mapping is a hemi-relatively nonexpansive mapping, but the converse is not true. 
Next, we give an example which is a closed hemirelatively nonexpansive mapping.

Example 2. Let $\Pi_{C}$ be the generalized projection from a smooth, strictly convex, and reflexive Banach space $E$ onto a nonempty closed convex subset $C \subset E$. Then $\Pi_{C}$ is a relatively nonexpansive mapping, and then it is also a closed hemirelatively nonexpansive mapping.

In 2005, Matsushita and Takahashi [13] obtained strong convergence theorems for a single relatively nonexpansive mapping in a uniformly convex and uniformly smooth Banach space $E$. To be more precise, they proved the following theorem.

Theorem MT (see Matsushita and Takahashi [13, Theorem 3.1]). Let $E$ be precisely a uniformly convex and uniformly smooth Banach space and $C$ a nonempty closed convex subset of $E$, and let $T$ be a relatively nonexpansive mapping from $C$ into itself, and let $\left\{\alpha_{n}\right\}$ be a sequence of real numbers such that $0 \leq \alpha_{n}<1$ and $\lim \sup _{n \rightarrow \infty} \alpha_{n}<1$. Suppose that $\left\{x_{n}\right\}$ is given by

$$
\begin{gathered}
x_{0}=x \in C, \\
y_{n}=\Pi_{C}\left(\alpha_{n} J x_{n}+\left(1-\alpha_{n}\right) J T x_{n}\right), \\
C_{n}=\left\{z \in C: \phi\left(z, y_{n}\right) \leq \phi\left(z, x_{n}\right)\right\}, \\
Q_{n}=\left\{z \in C:\left\langle x_{n}-z, J x-J x_{n}\right\rangle \geq 0\right\}, \\
x_{n+1}=\prod_{C_{n} \cap Q_{n}} x, \quad \forall n \in \mathbb{N} \cup\{0\},
\end{gathered}
$$

where $J$ is the duality mapping on E. If $F(T)$ is nonempty, then $\left\{x_{n}\right\}$ converges strongly to $\Pi_{F(T)} x$, where $\Pi_{F(T)}$ is the generalized projection from $C$ onto $F(T)$.

Since then, algorithms constructed for solving the same equilibrium problem, variational inequality problems, and fixed point of relatively nonexpansive mappings (or weak relatively nonexpansive mappings or hemi-relatively nonexpanisve mappings) have been further developed by many authors. For a part of works related to these problems, please see $[4,15-18]$, and for the hybrid algorithm projection methods for these problems, please see [19-44] and the references therein.

Motivated and inspired by the results in the literature, in this paper we focus our attention on finding a common fixed point of two countable families of hemi-relatively nonexpansive mappings (we shall give the definition of a countable family of hemi-relatively nonexpansive mappings in the next section) by using a simple hybrid algorithm. Furthermore, we will give some applications of our main result in equilibrium problems, variational inequality problems, and convex feasibility problems.

\section{Preliminaries}

Let $C$ be a closed convex subset of $E$, and let $\left\{T_{n}\right\}_{n=0}^{\infty}$ be a countable family of mappings from $C$ into itself. We denote by $F$ the set of common fixed points of $\left\{T_{n}\right\}_{n=0}^{\infty}$. That is,
$F=\bigcap_{n=0}^{\infty} F\left(T_{n}\right)$, where $F\left(T_{n}\right)$ denote the set of fixed points of $T_{n}$, for all $n \in \mathbb{N} \cup\{0\}$.

Recall that $\left\{T_{n}\right\}_{n=0}^{\infty}$ is said to be uniformly closed, if $p \in$ $\bigcap_{n=1}^{\infty} F\left(T_{n}\right)$, whenever $\left\{x_{n}\right\} \subset C$ converges strongly to $p$ and $\left\|x_{n}-T_{n} x_{n}\right\| \rightarrow 0$ as $n \rightarrow \infty$ (see [45] for more details).

A point $p \in C$ is said to be an asymptotic fixed point of $\left\{T_{n}\right\}_{n=0}^{\infty}$ if $C$ contains a sequence $\left\{x_{n}\right\}$ which converges weakly to $p$ such that $\lim _{n \rightarrow \infty}\left\|T_{n} x_{n}-x_{n}\right\|=0$. The set of asymptotic fixed points of $\left\{T_{n}\right\}_{n=0}^{\infty}$ will be denoted by $\widehat{F}\left(\left\{T_{n}\right\}_{n=0}^{\infty}\right)$.

A point $p \in C$ is said to be a strong asymptotic fixed point of $\left\{T_{n}\right\}_{n=0}^{\infty}$ if $C$ contains a sequence $\left\{x_{n}\right\}$ which converges strongly to $p$ such that $\lim _{n \rightarrow \infty}\left\|T_{n} x_{n}-x_{n}\right\|=0$. The set of strong asymptotic fixed points of $\left\{T_{n}\right\}_{n=0}^{\infty}$ will be denoted by $\widetilde{F}\left(\left\{T_{n}\right\}_{n=0}^{\infty}\right)$.

Using the definition of (strong) asymptotic fixed point of $\left\{T_{n}\right\}_{n=0}^{\infty}$, Su et al. [46] introduced the following definitions.

Definition 3 (see Su et al. [46]). Countable family of mappings $\left\{T_{n}\right\}$ is said to be countable family of relatively nonexpansive mappings if $\widehat{F}\left(\left\{T_{n}\right\}_{n=0}^{\infty}\right)=F\left(\left\{T_{n}\right\}_{n=0}^{\infty}\right) \neq \emptyset$ and

$$
\phi\left(p, T_{n} x\right) \leq \phi(p, x), \quad \forall x \in C, p \in F\left(T_{n}\right), n \in \mathbb{N} \cup\{0\} .
$$

Definition 4 (see Su et al. [46]). Countable family of mappings $\left\{T_{n}\right\}$ is said to be countable family of weak relatively nonexpansive mappings if $\widetilde{F}\left(\left\{T_{n}\right\}_{n=0}^{\infty}\right)=F\left(\left\{T_{n}\right\}_{n=0}^{\infty}\right) \neq \emptyset$ and

$$
\phi\left(p, T_{n} x\right) \leq \phi(p, x), \quad \forall x \in C, p \in F\left(T_{n}\right), n \in \mathbb{N} \cup\{0\} .
$$

Now, we introduce the definition of countable family of hemi-relatively nonexpansive mappings which is more general than countable family of relatively nonexpansive mappings and countable family of weak relatively nonexpansive mappings.

Definition 5. Countable family of mappings $\left\{T_{n}\right\}$ is said to be countable family of hemi-relatively nonexpansive mappings if $F\left(\left\{T_{n}\right\}_{n=0}^{\infty}\right) \neq \emptyset$ and

$$
\phi\left(p, T_{n} x\right) \leq \phi(p, x), \quad \forall x \in C, p \in F\left(T_{n}\right), n \in \mathbb{N} \cup\{0\} .
$$

Remark 6. From Definitions 3-5, one has the following facts.

(1) The definitions of relatively nonexpansive mapping, weak relatively nonexpansive mapping, and hemirelatively nonexpansive mapping are special cases of Definitions 3,4 , and 5 as $T_{n} \equiv T$ for all $n \in \mathbb{N} \cup\{0\}$.

(2) Countable family of hemi-relatively nonexpansive mappings, which do not need the restriction $\widehat{F}\left(\left\{T_{n}\right\}_{n=0}^{\infty}\right)=F\left(\left\{T_{n}\right\}_{n=0}^{\infty}\right)\left(\right.$ or $\left.\widetilde{F}\left(\left\{T_{n}\right\}_{n=0}^{\infty}\right)=F\left(\left\{T_{n}\right\}_{n=0}^{\infty}\right)\right)$, is more general than countable family of relatively nonexpansive mappings (or countable family of weak relatively nonexpansive mappings).

Next we give an example which is a countable family of hemi-relatively nonexpansive mappings but not a countable family of relatively nonexpansive mappings. 
Example 7. Let $E$ be any smooth Banach space and $x_{0}=(1+$ $1 / n)^{n} x_{0} \neq 0$ any element of $E$. Define a countable family of mappings $T_{n}: E \rightarrow E$ as follows: for all $n \geq 1$,

$$
T_{n}(x)= \begin{cases}\left(\frac{1}{2}+\frac{1}{2^{n+1}}\right) x_{0}, & \text { if } x=\left(\frac{1}{2}+\frac{1}{2^{n}}\right) x_{0}, \\ -x, & \text { if } x \neq\left(\frac{1}{2}+\frac{1}{2^{n}}\right) x_{0} .\end{cases}
$$

Then $\left\{T_{n}\right\}_{n=1}^{\infty}$ is a countable family of hemi-relatively nonexpansive mappings but not a countable family of relatively nonexpansive mappings.

Proof. First, it is obvious that $T_{n}$ has a unique fixed point 0 ; that is, $F\left(T_{n}\right)=\{0\}$ for all $n \geq 1$. In addition, one easily sees that

$$
\left\|T_{n} x\right\| \leq\|x\|, \quad \forall x \in E, n \geq 1 .
$$

This implies that

$$
\left\|T_{n} x\right\|^{2}-\|x\|^{2} \leq 2\left\langle 0, J T_{n} x-J x\right\rangle=2\left\langle p, J T_{n} x-J x\right\rangle,
$$

for all $p \in \bigcap_{n=1}^{\infty} F\left(T_{n}\right)$. It follows from the above inequality that

$$
\|p\|^{2}-2\left\langle p, J T_{n} x\right\rangle+\left\|T_{n} x\right\|^{2} \leq\|p\|^{2}-2\langle p, J x\rangle+\|x\|^{2},
$$

for all $p \in \bigcap_{n=1}^{\infty} F\left(T_{n}\right)$ and $x \in E$. That is,

$$
\phi\left(p, T_{n} x\right) \leq \phi(p, x),
$$

for all $p \in \bigcap_{n=1}^{\infty} F\left(T_{n}\right)$ and $x \in E$. Hence, $\left\{T_{n}\right\}_{n=1}^{\infty}$ is a countable family of hemi-relatively nonexpansive mappings. On the other hand, letting

$$
x_{n}=\left(\frac{1}{2}+\frac{1}{2^{n}}\right) x_{0}, \quad \forall n \geq 1,
$$

from the definition of $T_{n}$, one has

$$
T_{n} x_{n}=\left(\frac{1}{2}+\frac{1}{2^{n+1}}\right) x_{0}, \quad \forall n \geq 1,
$$

which implies that $\left\|x_{n}-T_{n} x_{n}\right\| \rightarrow 0$ and $x_{n} \rightarrow e \breve{x}_{0}\left(x_{n} \rightarrow\right.$ $\left.e \breve{x}_{0}\right)$ as $n \rightarrow \infty$. That is, $e \breve{x}_{0} \in \widehat{F}\left(\left\{T_{n}\right\}_{n=0}^{\infty}\right)$ but $e \breve{x}_{0} \notin$ $F\left(\left\{T_{n}\right\}_{n=0}^{\infty}\right)$, which shows that $\left\{T_{n}\right\}_{n=1}^{\infty}$ is not a countable family of relatively nonexpansive mappings.

In what follows, we will need the following lemmas.

Lemma 8 (see Alber [47]). Let $C$ be a convex subset of a smooth real Banach space E. Let $x \in E$ and $x_{0} \in C$. Then $x_{0}=\Pi_{C} x$ if and only if

$$
\left\langle z-x_{0}, J x_{0}-J x\right\rangle \geq 0, \quad \forall z \in C .
$$

Lemma 9 (see Alber [47]). Let $C$ be a nonempty, closed, and convex subset of a reflexive, strictly convex, and smooth real Banach space $E$, and let $x \in E$. Then for each $y \in C$,

$$
\phi\left(y, \Pi_{C} x\right)+\phi\left(\Pi_{C} x, x\right) \leq \phi(y, x) .
$$

Lemma 10 (see Kamimura and Takahashi [48]). Let $E$ be a uniformly convex and smooth real Banach space, and let $\left\{x_{n}\right\}$, $\left\{y_{n}\right\}$ be two sequences of $E$. If $\phi\left(x_{n}, y_{n}\right) \rightarrow 0$ and either $\left\{x_{n}\right\}$ or $\left\{y_{n}\right\}$ is bounded, then $\left\|x_{n}-y_{n}\right\| \rightarrow 0$.

\section{Main Results}

Now, we give our main results in this paper.

Theorem 11. Let $C$ be a nonempty, closed, and convex subset of a uniformly smooth and uniformly convex Banach space E. Let $\left\{S_{n}\right\},\left\{T_{n}\right\}$ be two uniformly closed countable families of hemirelatively nonexpansive mappings from $C$ into itself such that

$$
\mathscr{F}=\left\{\bigcap_{n=1}^{\infty} F\left(S_{n}\right)\right\} \bigcap\left\{\bigcap_{n=1}^{\infty} F\left(T_{n}\right)\right\} \neq \emptyset .
$$

For a point $x_{0} \in C$ chosen arbitrarily, let $\left\{x_{n}\right\}$ be a sequence generated by the following iterative algorithm:

$$
\begin{gathered}
C_{0}=C, \\
C_{n+1}=\left\{z \in C_{n}: \phi\left(z, S_{n} y_{n}\right) \leq \phi\left(z, T_{n} x_{n}\right) \leq \phi\left(z, x_{n}\right)\right\}, \\
x_{n+1}=\Pi_{C_{n+1}} x_{0},
\end{gathered}
$$

where the sequences $y_{n}=T_{n} x_{n}$. Then the sequence $\left\{x_{n}\right\}$ converges strongly to a point $q=\Pi_{\mathscr{F}} x_{0}$, where $\Pi_{\mathscr{F}}$ is the generalized projection from $C$ onto $\mathscr{F}$.

Proof. We first show that $C_{n+1}$ is closed and convex. It is obvious that $C_{n+1}$ is closed. Since

$$
\begin{aligned}
\phi\left(z, S_{n} y_{n}\right) & \leq \phi\left(z, T_{n} x_{n}\right) \\
& \Longleftrightarrow\left\|S_{n} y_{n}\right\|^{2}-\left\|T_{n} x_{n}\right\| \\
& -2\left\langle z, J S_{n} y_{n}-J T_{n} x_{n}\right\rangle \geq 0, \\
\phi\left(z, T_{n} x_{n}\right) & \leq \phi\left(z, x_{n}\right) \\
& \Longleftrightarrow\left\|T_{n} x_{n}\right\|^{2}-\left\|x_{n}\right\| \\
& -2\left\langle z, J T_{n} x_{n}-J x_{n}\right\rangle \geq 0,
\end{aligned}
$$

$C_{n+1}$ is convex. Therefore, $C_{n+1}$ is closed and convex for all $n \in \mathbb{N} \cup\{0\}$.

Let $u \in \mathscr{F}$; from the definition of $S_{n}$ and $T_{n}$, we have

$$
\phi\left(u, S_{n} y_{n}\right) \leq \phi\left(u, y_{n}\right)=\phi\left(u, T_{n} x_{n}\right) \leq \phi\left(u, x_{n}\right) .
$$

Hence, we have $u \in C_{n+1}$. This implies that $\mathscr{F} \subset C_{n+1}$ for arbitrary $n \in \mathbb{N} \cup\{0\}$.

Noticing $x_{n}=\Pi_{C_{n}} x_{0}$, from Lemma 8, we have

$$
\left\langle x_{n}-z, J x_{0}-J x_{n}\right\rangle \geq 0, \quad \forall z \in C_{n} .
$$

Since $\mathscr{F} \subset C_{n}$ for all $n \in \mathbb{N} \cup\{0\}$, we arrive at

$$
\left\langle x_{n}-p, J x_{0}-J x_{n}\right\rangle \geq 0, \quad \forall p \in \mathscr{F} .
$$

From Lemma 9, we have

$$
\begin{aligned}
\phi\left(x_{n}, x_{0}\right) & =\phi\left(\Pi_{C_{n}} x_{0}, x_{0}\right) \\
& \leq \phi\left(p, x_{0}\right)-\phi\left(p, x_{n}\right) \leq \phi\left(p, x_{0}\right)
\end{aligned}
$$


for each $p \in \mathscr{F} \subset C_{n}$ and for all $n \in \mathbb{N} \cup\{0\}$. So the sequence $\left\{\phi\left(x_{n}, x_{0}\right)\right\}$ is bounded. On the other hand, noticing that $x_{n}=$ $\Pi_{C_{n}} x_{0}$ and $x_{n+1}=\Pi_{C_{n+1}} x_{0} \in C_{n+1} \subset C_{n}$, we have

$$
\phi\left(x_{n}, x_{0}\right) \leq \phi\left(x_{n+1}, x_{0}\right), \quad \forall n \in \mathbb{N} \cup\{0\} .
$$

This implies that the sequence $\left\{\phi\left(x_{n}, x_{0}\right)\right\}$ is nondecreasing. It follows that the limit of $\left\{\phi\left(x_{n}, x_{0}\right)\right\}$ exists. By the construction of $C_{n}$, we have that $x_{m}=\Pi_{C_{m}} x_{0} \in C_{m} \subset C_{n}$ for any positive integer $m \geq n$. It follows that

$$
\phi\left(x_{m}, x_{n}\right)=\phi\left(x_{m}, \Pi_{C_{n}} x_{0}\right) \leq \phi\left(x_{m}, x_{0}\right)-\phi\left(x_{n}, x_{0}\right) .
$$

Letting $m, n \rightarrow \infty$ in (40), by the existence of the limit of $\left\{\phi\left(x_{n}, x_{0}\right)\right\}$, we have $\phi\left(x_{m}, x_{n}\right) \rightarrow 0$. It follows from Lemma 10 that $x_{n}-x_{m} \rightarrow 0$ as $m, n \rightarrow \infty$. Hence $\left\{x_{n}\right\}$ is a Cauchy sequence. Therefore, there exists a point $q \in C$ such that $x_{n} \rightarrow q$ as $n \rightarrow \infty$.

Since $x_{n+1}=\Pi_{C_{n+1}} x_{0} \in C_{n+1} \subset C_{n}$, we have from the definition of $C_{n+1}$ that

$$
\begin{aligned}
\phi\left(x_{n+1}, S_{n} y_{n}\right) & \leq \phi\left(x_{n+1}, T_{n} x_{n}\right) \\
& \leq \phi\left(x_{n+1}, x_{n}\right), \quad \forall n \in \mathbb{N} \cup\{0\} .
\end{aligned}
$$

From the inequality above, we have

$$
\begin{array}{ll}
\phi\left(x_{n+1}, T_{n} x_{n}\right) \leq \phi\left(x_{n+1}, x_{n}\right), & \forall n \in \mathbb{N} \cup\{0\}, \\
\phi\left(x_{n+1}, S_{n} y_{n}\right) \leq \phi\left(x_{n+1}, x_{n}\right), & \forall n \in \mathbb{N} \cup\{0\} .
\end{array}
$$

On the other hand, taking $m=n+1$ in (40), we have

$$
\lim _{n \rightarrow \infty} \phi\left(x_{n+1}, x_{n}\right)=0 .
$$

From (42) and (43), we have that

$$
\begin{aligned}
& \lim _{n \rightarrow \infty} \phi\left(x_{n+1}, T_{n} x_{n}\right)=0, \\
& \lim _{n \rightarrow \infty} \phi\left(x_{n+1}, S_{n} y_{n}\right)=0 .
\end{aligned}
$$
that

By using Lemma 10, the inequalities (43) and (44) follow

$$
\begin{aligned}
& \lim _{n \rightarrow \infty}\left\|x_{n+1}-x_{n}\right\|=0, \\
& \lim _{n \rightarrow \infty}\left\|x_{n+1}-T_{n} x_{n}\right\|=0, \\
& \lim _{n \rightarrow \infty}\left\|x_{n+1}-S_{n} y_{n}\right\|=0 .
\end{aligned}
$$

Respectively, noticing that

$$
\begin{aligned}
\left\|x_{n}-T_{n} x_{n}\right\| & =\left\|x_{n}-x_{n+1}+x_{n+1}-T_{n} x_{n}\right\| \\
& \leq\left\|x_{n}-x_{n+1}\right\|+\left\|x_{n+1}-T_{n} x_{n}\right\| .
\end{aligned}
$$

It follows from (45) and (46) that

$$
\lim _{n \rightarrow \infty}\left\|x_{n}-T_{n} x_{n}\right\|=0 .
$$

From uniform closedness of $\left\{T_{n}\right\}$, we get $q \in \bigcap_{n=1}^{\infty} F\left(T_{n}\right)$. On the other hand, noticing that $y_{n}=T_{n} x_{n}$, we have

$$
\begin{aligned}
& \lim _{n \rightarrow \infty} y_{n}=\lim _{n \rightarrow \infty} x_{n}=q, \\
& \left\|y_{n}-S_{n} y_{n}\right\|=\left\|y_{n}-x_{n+1}+x_{n+1}-S_{n} y_{n}\right\| \\
& \leq\left\|y_{n}-x_{n+1}\right\|+\left\|x_{n+1}-S_{n} y_{n}\right\| \\
& \leq\left\|T_{n} x_{n}-x_{n+1}\right\|+\left\|x_{n+1}-S_{n} y_{n}\right\| .
\end{aligned}
$$

It follows from (46) and (47) that

$$
\lim _{n \rightarrow \infty}\left\|y_{n}-S_{n} y_{n}\right\|=0 \text {. }
$$

From uniform closedness of $\left\{S_{n}\right\}$, we also have $q \in$ $\bigcap_{n=1}^{\infty} F\left(S_{n}\right)$. Therefore, $q \in \mathscr{F}$. have

Finally, we show that $q=\Pi_{\mathscr{F}} x_{0}$. From $x_{n}=\Pi_{C_{n}} x_{0}$, we

$$
\left\langle x_{n}-p, J x_{0}-J x_{n}\right\rangle \geq 0, \quad \forall p \in \mathscr{F} \subset C_{n} .
$$

Taking the limit as $n \rightarrow \infty$ in (52), we obtain

$$
\left\langle q-p, J x_{0}-J q\right\rangle \geq 0, \quad \forall p \in \mathscr{F},
$$

and hence $p=\Pi_{\mathscr{F}} x_{0}$ from Lemma 8. This completes the proof.

Remark 12. Theorem 11 improves Theorem 3.15 of Zhang et al. [49] in the following senses:

(1) from the class of a countable family of weak relatively nonexpansive mappings to the one of a countable family of hemi-relatively nonexpansive mappings;

(2) from a single countable family of mappings to two countable families of mappings.

When $T_{n}=I$ in (32), we can obtain the following corollary immediately.

Corollary 13. Let $C$ be a nonempty, closed and convex subset of a uniformly smooth and uniformly convex Banach space E. Let $\left\{S_{n}\right\}$ be a uniformly closed countable family of hemi-relatively nonexpansive mappings from $C$ into itself such that

$$
\mathscr{F}=\left\{\bigcap_{n=1}^{\infty} F\left(S_{n}\right)\right\} \neq \emptyset .
$$

For a point $x_{0} \in C$ chosen arbitrarily, let $\left\{x_{n}\right\}$ be a sequence generated by the following iterative algorithm:

$$
\begin{gathered}
C_{0}=C, \\
C_{n+1}=\left\{z \in C_{n}: \phi\left(z, S_{n} x_{n}\right) \leq \phi\left(z, x_{n}\right)\right\}, \\
x_{n+1}=\Pi_{C_{n+1}} x_{0} .
\end{gathered}
$$

Then the sequence $\left\{x_{n}\right\}$ converges strongly to a point $q=\Pi_{\mathscr{F}} x_{0}$, where $\Pi_{\mathscr{F}}$ is the generalized projection from $C$ onto $\mathscr{F}$.

Remark 14. We notice that if $\left\{S_{n}\right\}$ is a countable family of weak relatively nonexpansive mappings, Corollary 13 is still held. Therefore, Corollary 13 extends and improves Theorem 3.15 in [49]. 


\section{Applications to Convex Feasibility Problems}

In this section, we consider the following convex feasibility problem (CFP):

$$
\text { finding an } x \in \bigcap_{n=1}^{\infty} C_{n} \text {, }
$$

where $n \in \mathbb{N} \cup\{0\}$, and $\left\{C_{n}\right\}_{n=0}^{\infty}$ is an intersecting closed convex subset sequence of a Banach space $E$. This problem is a frequently appearing problem in diverse areas of mathematical and physical sciences. There is a considerable investigation on (CFP) in the framework of Hilbert spaces which captures applications in various disciplines such as image restoration [50-53], computer tomography [54], and radiation therapy treatment planning [55]. In computer tomography with limited data, in which an unknown image has to be reconstructed from a priori knowledge and from measured results, each piece of information gives a constraint which in turn gives rise to a convex set $C_{n}$ to which the unknown image should belong (see [56]).

Using Theorem 11, we discuss the convex feasibility problems as an application.

Theorem 15. Let $C$ be a nonempty, closed, and convex subset of a uniformly smooth and uniformly convex Banach space E. Let $\left\{\Omega_{n}\right\}_{n=0}^{\infty},\left\{\Omega_{n}^{*}\right\}_{n=0}^{\infty}$ be two countable families of nonempty closed convex subset of $C$ such that

$$
\Omega=\left\{\bigcap_{n=0}^{\infty} \Omega_{n}\right\} \bigcap\left\{\bigcap_{n=0}^{\infty} \Omega_{n}^{*}\right\} \neq \emptyset .
$$

For a point $x_{0} \in C$ chosen arbitrarily, let $\left\{x_{n}\right\}$ be a sequence generated by the following iterative algorithm:

$$
\begin{gathered}
C_{0}=C, \\
C_{n+1}=\left\{z \in C_{n}: \phi\left(z, \Pi_{\Omega_{n}} y_{n}\right) \leq \phi\left(z, \Pi_{\Omega_{n}^{*}} x_{n}\right) \leq \phi\left(z, x_{n}\right)\right\}, \\
x_{n+1}=\Pi_{C_{n+1}} x_{0},
\end{gathered}
$$

where the sequences $y_{n}=\Pi_{\Omega_{n}^{*}} x_{n}$. Then the sequence $\left\{x_{n}\right\}$ converges strongly to a point $q=\Pi_{\Omega} x_{0}$, where $\Pi_{\Omega}$ is the generalized projection from $C$ onto $\Omega$.

Proof. From Lemma 9, we easily have that $\left\{\Pi_{\Omega_{n}}\right\}$ and $\left\{\Pi_{\Omega_{n}^{*}}\right\}$ are two countable families of hemi-relatively nonexpansive mappings. In view of the continuity of $\Pi_{\Omega_{n}}$ and $\Pi_{\Omega_{n}^{*}}$, we have that $\left\{\Pi_{\Omega_{n}}\right\}$ and $\left\{\Pi_{\Omega_{n}^{*}}\right\}$ are two uniformly closed countable families of hemi-relatively nonexpansive mappings. Thus, by using Theorem 11, we have that the sequence $\left\{x_{n}\right\}$ converges strongly to a point $q=\Pi_{\Omega} x_{0}$. This completes the proof.

If we only consider a countable family of nonempty closed convex subset of $C$, the following corollary can be obtained by using Theorem 15.

Corollary 16. Let $C$ be a nonempty, closed, and convex subset of a uniformly smooth and uniformly convex Banach space E.
Let $\left\{\Omega_{n}\right\}_{n=0}^{\infty}$ be a countable family of nonempty closed convex subset of $C$ such that

$$
\Omega=\left\{\bigcap_{n=0}^{\infty} \Omega_{n}\right\} \neq \emptyset .
$$

For a point $x_{0} \in C$ chosen arbitrarily, let $\left\{x_{n}\right\}$ be a sequence generated by the following iterative algorithm:

$$
\begin{gathered}
C_{0}=C, \\
C_{n+1}=\left\{z \in C_{n}: \phi\left(z, \Pi_{\Omega_{n}} x_{n}\right) \leq \phi\left(z, x_{n}\right)\right\}, \\
x_{n+1}=\Pi_{C_{n+1}} x_{0} .
\end{gathered}
$$

Then the sequence $\left\{x_{n}\right\}$ converges strongly to a point $q=\Pi_{\Omega} x_{0}$, where $\Pi_{\Omega}$ is the generalized projection from $C$ onto $\Omega$.

Proof. Putting $\Pi_{\Omega_{n}^{*}} \equiv I$ for all $n \in \mathbb{N} \cup\{0\}$ in algorithm (58), the conclusion can be obtained from Theorem 15 immediately.

\section{Applications to Generalized Mixed Equilibrium Problems}

In this section, we apply our main results to prove some strong convergence theorems concerning generalized mixed equilibrium problems in a Banach space $E$.

Let $A: C \rightarrow E^{*}$ be a mapping. First, we recall the following definition:

(I) $A$ is called monotone if

$$
\langle A x-A y, x-y\rangle \geq 0, \quad \forall x, y \in C
$$

(II) $A$ is called $\alpha$-inverse strongly monotone if there exists a constant $\alpha>0$ such that

$$
\langle A x-A y, x-y\rangle \geq \alpha\|A x-A y\|^{2}, \quad \forall x, y \in C .
$$

We remark here that an $\alpha$-inverse strongly monotone $A$ is $(1 / \alpha)$-Lipschitz continuous.

For solving the generalized mixed equilibrium problem (1), let us assume that the nonlinear mapping $A: C \rightarrow E^{*}$ is monotone and continuous, the function $\varphi: C \rightarrow \mathbb{R}$ is convex and lower semicontinuous, and the bifunction $f: C \times$ $C \rightarrow \mathbb{R}$ satisfies the following conditions:

$\left(A_{1}\right) f(x, x)=0$, for all $x \in C$;

$\left(A_{2}\right) f$ is monotone, that is, $f(x, y)+f(y, x) \leq 0$, for all $x, y \in C$;

$\left(A_{3}\right) \lim \sup _{t \downarrow 0} f(x+t(z-x), y) \leq f(x, y)$, for all $x, y, z \in$ C;

$\left(A_{4}\right)$ the function $y \mapsto f(x, y)$ is convex and lower semicontinuous for all $x \in C$.

The following result can be found in Blum and Oettli [1].

Lemma 17 (see Blum and Oettli [1]). Let $C$ be a closed convex subset of a smooth, strictly convex, and reflexive Banach space 
$E$, let $f$ be a bifunction from $C \times C$ to $\mathbb{R}$ satisfying $\left(A_{1}\right)-\left(A_{4}\right)$, and let $r>0$ and $x \in E$. Then, there exists $z \in C$ such that

$$
f(z, y)+\frac{1}{r}\langle y-z, J z-J x\rangle \geq 0, \quad \forall y \in C .
$$

Lemma 18. Let $C$ be a closed convex subset of a smooth, strictly convex, and reflexive Banach space $E$, let $A: C \rightarrow E^{*}$ be a monotone and continuous mapping, let the function $\varphi$ : $C \rightarrow \mathbb{R}$ be convex and lower semicontinuous, and let $f$ be a bifunction from $C \times C$ to $\mathbb{R}$ satisfying $\left(A_{1}\right)-\left(A_{4}\right)$. Then, $f(x, y)+\langle A x, y-x\rangle+\varphi(y)-\varphi(x)$ satisfies $\left(A_{1}\right)-\left(A_{4}\right)$.

Proof. For convenience, we set $F(x, y)=f(x, y)+\langle A x, y-$ $x\rangle+\varphi(y)-\varphi(x)$. So, we only need to prove that $F(x, y)$ satisfies $\left(A_{1}\right)-\left(A_{4}\right)$.

(I) We show that $F(x, x)=0$, for all $x \in C$. Since $f(x, y)$ satisfies $\left(A_{1}\right)$, we have

$$
\begin{aligned}
F(x, x)= & f(x, x)+\langle A x, x-x\rangle \\
& +\varphi(x)-\varphi(x)=f(x, x)=0, \quad \forall x \in C .
\end{aligned}
$$

(II) We show that $F$ is monotone; that is, $F(x, y)+$ $F(y, x) \leq 0$, for all $x, y \in C$; since $A$ is continuous and monotone, from $\left(A_{2}\right)$, we have

$$
\begin{aligned}
& F(x, y)+F(y, x) \\
&= f(x, y)+\langle A x, y-x\rangle+\varphi(y)-\varphi(x) \\
&+f(y, x)+\langle A y, x-y\rangle+\varphi(x)-\varphi(y) \\
&= f(x, y)+\langle A x, y-x\rangle+f(y, x)+\langle A y, x-y\rangle \\
& \leq 0+\langle A x-A y, y-x\rangle=-\langle A y-A z, y-x\rangle \leq 0 .
\end{aligned}
$$

(III) We show that $\lim \sup _{t \downarrow 0} F(x+t(z-x), y) \leq F(x, y)$, for all $x, y, z \in C$; Since $A$ is continuous and $\varphi$ is lower semicontinuous, we have

$$
\begin{aligned}
& \limsup _{t \downarrow 0} F(x+t(z-x), y) \\
& =\limsup _{t \downarrow 0} f(x+t(z-x), y) \\
& \quad+\limsup _{t \downarrow 0}\langle A(x+t(z-x)), y-(x+t(z-x))\rangle \\
& \quad+\limsup _{t \downarrow 0}[\varphi(y)-\varphi(x+t(z-x))] \\
& \quad \leq f(x, y)+\langle A x, y-x\rangle+\varphi(y)-\varphi(x)=F(x, y) .
\end{aligned}
$$

(IV) We show that the function $y \mapsto F(x, y)$ is convex and lower semicontinuous for each $x \in C$.
For each $x \in C$, for all $t \in(0,1)$ and for all $y, z \in C$, since $f$ satisfies $\left(A_{4}\right)$ and $\varphi$ is convex, we have

$$
\begin{aligned}
& F(x, t y+(1-t) z) \\
&= f(x, t y+(1-t) z) \\
&+\langle A x, t y+(1-t) z-x\rangle \\
&+\varphi(t y+(1-t) z)-\varphi(x) \\
&= t[f(x, y)+\langle A x, y-x\rangle+\varphi(y)-\varphi(x)] \\
&+(1-t)[f(x, t)+\langle A x, z-x\rangle+\varphi(z)-\varphi(x)] \\
&= t F(x, y)+(1-t) F(x, z) .
\end{aligned}
$$

This completes the proof.

Lemma 19 (see Takahashi and Zembayashi [17]). Let C be a closed convex subset of a uniformly smooth, strictly convex, and reflexive Banach space $E$, and let $f$ be a bifunction from $C \times C$ to $\mathbb{R}$ satisfying $\left(A_{1}\right)-\left(A_{4}\right)$. For $r>0$ and $x \in E$, define a mapping $T_{r}: E \rightarrow C$ as follows:

$$
\begin{gathered}
T_{r}(x)=\left\{z \in C: f(z, y)+\frac{1}{r}\langle y-z, J z-J x\rangle\right. \\
\geq 0, \forall y \in C\}
\end{gathered}
$$

for all $x \in E$. Then, the following properties hold:

(1) $T_{r}$ is single valued;

(2) $T_{r}$ is a firmly nonexpansive-type mapping; that is, for all $x, y \in E$,

$\left\langle T_{r} x-T_{r} y, J T_{r} x-J T_{r} y\right\rangle \leq\left\langle T_{r} x-T_{r} y, J x-J y\right\rangle ;$

(3) $\mathrm{EP}(f)=F\left(T_{r}\right)=\widehat{F}\left(T_{r}\right)$;

(4) $\mathrm{EP}(f)$ is closed and convex;

(5) $\phi\left(q, T_{r} x\right)+\phi\left(T_{r} x, x\right) \leq \phi(q, x)$, for all $x \in E, q \in$ $F\left(T_{r}\right)$.

Lemma 20 (see Zhang et al. [57]). Let E be a p-uniformly convex with $p \geq 0$ and uniformly smooth Banach space, and let $C$ be a nonempty closed convex subset of $E$. Let $f$ be a bifunction from $C \times C$ to $\mathbb{R}$ satisfying $\left(A_{1}\right)-\left(A_{4}\right)$. Let $\left\{r_{n}\right\}$ be a positive real sequence such that $\lim _{n \rightarrow \infty} r_{n}=r>0$. Then the sequence of mappings $T_{r_{n}}$ is uniformly closed.

Next, we shall apply Theorem 11 to solve two generalized mixed equilibrium problems. To accomplish this purpose, let $A, B: C \rightarrow E^{*}$ be two monotone and continuous mappings, let the function $\varphi, \psi: C \rightarrow \mathbb{R}$ be convex and lower semicontinuous, and let $f$ and $g$ be a bifunction from 
$C \times C$ to $\mathbb{R}$ satisfying $\left(A_{1}\right)-\left(A_{4}\right)$. For $r>0$ and $x \in E$, define two mappings $J_{r}, K_{r}: E \rightarrow C$ as follows:

$$
\begin{gathered}
J_{r}(x)=\{z \in C: f(z, y)+\langle A z, y-z\rangle+\varphi(y)-\varphi(z) \\
\left.+\frac{1}{r}\langle y-z, J z-J x\rangle \geq 0, \forall y \in C\right\}, \\
K_{r}(x)=\{z \in C: g(z, y)+\langle B z, y-z\rangle+\psi(y)-\psi(z) \\
\left.+\frac{1}{r}\langle y-z, J z-J x\rangle \geq 0, \forall y \in C\right\} .
\end{gathered}
$$

Theorem 21. Let $E$ be a p-uniformly convex with $p \geq 2$ and uniformly smooth Banach space, and let $C$ be a nonempty closed convex subset of $E$. Let $A, B: C \rightarrow E^{*}$ be two monotone and continuous mappings, let the function $\varphi, \psi: C \rightarrow \mathbb{R}$ be convex and lower semicontinuous, and let $f$ and $g$ be $a$ bifunction from $C \times C$ to $\mathbb{R}$ satisfying $\left(A_{1}\right)-\left(A_{4}\right)$ such that $\mathfrak{I}=\operatorname{GMEP}(f, A, \varphi) \bigcap \operatorname{GMEP}(g, B, \psi) \neq \emptyset$. For a point $x_{0} \in$ $C$ chosen arbitrarily, let $\left\{x_{n}\right\}$ be a sequence generated by the following iterative algorithm:

$$
\begin{gathered}
C_{0}=C, \\
C_{n+1}=\left\{z \in C_{n}: \phi\left(z, v_{n}\right) \leq \phi\left(z, u_{n}\right) \leq \phi\left(z, x_{n}\right)\right\}, \\
x_{n+1}=\prod_{C_{n+1}} x_{0},
\end{gathered}
$$

where $u_{n}=J_{r_{n}} x_{n}, v_{n}=K_{r_{n}} u_{n}$, and $\lim _{n \rightarrow \infty} r_{n}=r$. Then the sequence $\left\{x_{n}\right\}^{n}$ converges strongly to a point $q=\Pi_{\mathfrak{J}} x_{0}$, where $\Pi_{\mathfrak{J}}$ is the generalized projection from $\mathrm{C}$ onto $\mathfrak{\Im}$.

Proof. From Lemmas 18 and 20, we learn that $\left\{J_{r_{n}}\right\}$ and $\left\{K_{r_{n}}\right\}$ are uniformly closed. And by Lemma 19 (5), one can easily get that $\left\{J_{r_{n}}\right\}$ and $\left\{K_{r_{n}}\right\}$ are uniformly closed countable families of hemi-relatively nonexpansive mappings. Notice that if $E$ is $p$-uniformly convex, it must be uniformly convex. Therefore, by using Theorem 11, we can obtain the conclusion of Theorem 21. This completes the proof.

Theorem 22. Let $E$ be a p-uniformly convex with $p \geq 2$ and uniformly smooth Banach space, and let $C$ be a nonempty closed convex subset of $E$. Let $A: C \rightarrow E^{*}$ be a monotone and continuous mappings, let the function $\varphi: C \rightarrow \mathbb{R}$ be convex and lower semicontinuous and let $f$ be a bifunction from $C \times C$ to $\mathbb{R}$ satisfying $\left(A_{1}\right)-\left(A_{4}\right)$ such that $\mathfrak{J}=\operatorname{GMEP}(f, A, \varphi) \neq \emptyset$. For a point $x_{0} \in C$ chosen arbitrarily, let $\left\{x_{n}\right\}$ be a sequence generated by the following iterative algorithm:

$$
\begin{gathered}
C_{0}=C, \\
C_{n+1}=\left\{z \in C_{n}: \phi\left(z, u_{n}\right) \leq \phi\left(z, x_{n}\right)\right\}, \\
x_{n+1}=\Pi_{C_{n+1}} x_{0},
\end{gathered}
$$

where $u_{n}=J_{r_{n}} x_{n}$ and $\lim _{n \rightarrow \infty} r_{n}=r$. Then the sequence $\left\{x_{n}\right\}$ converges strongly to a point $q=\Pi_{\mathfrak{J}} x_{0}$, where $\Pi_{\mathfrak{J}}$ is the generalized projection from $C$ onto $\mathfrak{\Im}$.
Proof. From Lemmas 18 and 20, we learn that $\left\{J_{r_{n}}\right\}$ is uniformly closed. And by Lemma 19(5), one can easily get that $\left\{J_{r_{n}}\right\}$ is an uniformly closed countable family of hemirelatively nonexpansive mappings. Notice that if $E$ is $p$ uniformly convex, it must be uniformly convex. Therefore, by using Corollary 13, we can obtain the conclusion of Theorem 21. This completes the proof.

If we let $f \equiv 0, \varphi \equiv 0$ in (70) and $B \equiv 0, \psi \equiv 0$ in (71), the following corollary can be obtained by using Theorem 21 .

Corollary 23. Let $E$ be a p-uniformly convex with $p \geq 2$ and uniformly smooth Banach space, and let $C$ be a nonempty closed convex subset of $E$. Let $g$ be a bifunction from $C \times C$ to $\mathbb{R}$ satisfying $\left(A_{1}\right)-\left(A_{4}\right)$ and $A: C \rightarrow E^{*}$ a monotone and continuous mapping. Suppose that $\mathfrak{J}=\operatorname{VI}(A, C) \bigcap \operatorname{EP}(g) \neq \emptyset$. For a point $x_{0} \in C$ chosen arbitrarily, let $\left\{x_{n}\right\}$ be a sequence generated by the following iterative algorithm:

$$
\begin{gathered}
C_{0}=C, \\
C_{n+1}=\left\{z \in C_{n}: \phi\left(z, v_{n}\right) \leq \phi\left(z, u_{n}\right) \leq \phi\left(z, x_{n}\right)\right\}, \\
x_{n+1}=\Pi_{C_{n+1}} x_{0},
\end{gathered}
$$

where $u_{n}=J_{r_{n}} x_{n}, v_{n}=K_{r_{n}} u_{n}$, and $\lim _{n \rightarrow \infty} r_{n}=r$. Then the sequence $\left\{x_{n}\right\}$ converges strongly to a point $q=\Pi_{\mathfrak{J}} x_{0}$, where $\Pi_{\mathfrak{J}}$ is the generalized projection from $C$ onto $\mathfrak{\Im}$.

Remark 24. By analysis of special cases for generalized mixed equilibrium problem, we can obtain the corresponding results based on Theorems 21 and 22 in sequence. Here, we do not itemize these results.

\section{Applications to Maximal Monotone Operators}

Let $\mathscr{A}$ be a multivalued operator from $E$ to $E^{*}$ with domain $D(\mathscr{A})=\{z \in E: \mathscr{A} z \neq \emptyset\}$ and range $R(\mathscr{A})=\{z \in E: z \in$ $D(\mathscr{A})\}$. An operator $\mathscr{A}$ is said to be monotone if

$$
\begin{array}{r}
\left\langle x_{1}-x_{2}, y_{1}-y_{2}\right\rangle \geq 0, \quad \forall x_{1}, x_{2} \in D(\mathscr{A}), \\
y_{1} \in \mathscr{A} x_{1}, \quad y_{2} \in \mathscr{A} x_{2} .
\end{array}
$$

A monotone operator $\mathscr{A}$ is said to be maximal if its graph $G(\mathscr{A})=\{(x, y): y \in \mathscr{A} x\}$ is not properly contained in the graph of any other monotone operator. It is well known that if $\mathscr{A}$ is a maximal monotone operator, then $\mathscr{A}^{-1} 0$ is closed and convex.

The following result is also well known.

Lemma 25 (see Rockafellar [58]). Let E be a reflexive, strictly convex, and smooth Banach space and $\mathscr{A}$ a monotone operator from $E$ to $E^{*}$. Then $\mathscr{A}$ is maximal if and only if $R(J+r \mathscr{A})=E^{*}$ for all $r>0$.

Let $E$ be a reflexive, strictly convex, and smooth Banach space and $\mathscr{A}$ a maximal monotone operator from $E$ to $E^{*}$. Using Lemma 25 and the strict convexity of $E$, it follows that, 
for all $r>0$ and $x \in E$, there exists a unique $x_{r} \in D(\mathscr{A})$ such that

$$
J x \in J x_{r}+r \mathscr{A} x_{r} .
$$

If $J_{r} x=x_{r}$, then we can define a single-valued mapping $J_{r}: E \rightarrow D(\mathscr{A})$ by $J_{r}=(J+r \mathscr{A})^{-1} J$ and such a $J_{r}$ is called the resolvent of $\mathscr{A}$. We know that $\mathscr{A}^{-1} 0=F\left(J_{r}\right)$ for all $r>0$ (see $[10,59]$ for more details).

First, we give an important lemma for this section and remark that the following lemma can be as example of a countable family of hemi-relatively nonexpansive mappings.

Lemma 26. Let $E$ be a strictly convex and uniformly smooth Banach space, let $\mathscr{A}$ be a maximal monotone operator from $E$ to $E^{*}$ such that $\mathscr{A}^{-1} 0$ is nonempty, and let $\left\{r_{n}\right\}$ be a sequence of positive real numbers which is bounded away from 0 such that $J_{r_{n}}=\left(I+r_{n} \mathscr{A}\right)^{-1}$. Then $\left\{J_{r_{n}}\right\}$ is a uniformly closed countable family of hemi-relatively nonexpansive mappings.

Proof. One has $\bigcap_{n=0}^{\infty} F\left(J_{r_{n}}\right)=\mathscr{A}^{-1} 0 \neq \emptyset$. Firstly, we show $J_{r_{n}}$ is uniformly closed. Let $\left\{z_{n}\right\}$ be a sequence such that $z_{n} \rightarrow p$ and $\lim _{n \rightarrow \infty}\left\|z_{n}-J_{r_{n}} z_{n}\right\|=0$. Since $J$ is uniformly norm-tonorm continuous on bounded sets, we obtain

$$
\frac{1}{r_{n}}\left(J z_{n}-J J_{r_{n}} z_{n}\right) \longrightarrow 0, \quad \text { as } n \longrightarrow \infty
$$

It follows from

$$
\frac{1}{r_{n}}\left(J z_{n}-J J_{r_{n}} z_{n}\right) \in \mathscr{A} J_{r_{n}} z_{n}
$$

and the monotonicity of $B$ that

$$
\left\langle w-J_{r_{n}} z_{n}, w^{*}-\frac{1}{r_{n}}\left(J z_{n}-J J_{r_{n}} z_{n}\right)\right\rangle \geq 0
$$

for all $w \in D(\mathscr{A})$ and $w^{*} \in \mathscr{A} w$. Letting $n \rightarrow \infty$, one has $\left\langle w-p, w^{*}\right\rangle \geq 0$ for all $w \in D(\mathscr{A})$ and $w^{*} \in \mathscr{A} w$. Therefore, from the maximality of $\mathscr{A}$, one obtains $p \in \mathscr{A}^{-1} 0=F\left(J_{r_{n}}\right)$. Hence, $J_{r_{n}}$ is uniformly closed.

In addition, for any $w \in E$ and $p \in \bigcap_{n=0}^{\infty} F\left(J_{r_{n}}\right)$, from the monotonicity of $\mathscr{A}$, one has

$$
\begin{aligned}
\phi\left(p, J_{r_{n}} w\right)= & \|p\|^{2}-2\left\langle p, J J_{r_{n}} w\right\rangle+\left\|J_{r_{n}} w\right\|^{2} \\
= & \|p\|^{2}+2\left\langle p, J w-J J_{r_{n}} w-J w\right\rangle+\left\|J_{r_{n}} w\right\|^{2} \\
= & \|p\|^{2}+2\left\langle p, J w-J J_{r_{n}} w\right\rangle-2\langle p, J w\rangle+\left\|J_{r_{n}} w\right\|^{2} \\
= & \|p\|^{2}-2\left\langle J_{r_{n}} w-p-J_{r_{n}} w, J w-J J_{r_{n}} w-J w\right\rangle \\
& -2\langle p, J w\rangle+\left\|J_{r_{n}} w\right\|^{2}
\end{aligned}
$$

$$
\begin{aligned}
= & \|p\|^{2}-2\left\langle J_{r_{n}} w-p, J w-J J_{r_{n}} w-J w\right\rangle \\
& +2\left\langle J_{r_{n}} w, J w-J J_{r_{n}} w\right\rangle-2\langle p, J w\rangle+\left\|J_{r_{n}} w\right\|^{2} \\
\leq & \|p\|^{2}+2\left\langle J_{r_{n}} w, J w-J J_{r_{n}} w\right\rangle \\
& -2\langle p, J w\rangle+\left\|J_{r_{n}} w\right\|^{2} \\
= & \|p\|^{2}-2\langle p, J w\rangle+\|w\|^{2} \\
& -\left\|J_{r_{n}} w\right\|^{2}+2\left\langle J_{r_{n}} w, J w\right\rangle-\|w\|^{2} \\
= & \phi(p, w)-\phi\left(J_{r_{n}} w, w\right) \leq \phi(p, w),
\end{aligned}
$$

for all $n \in \mathbb{N} \cup\{0\}$. This implies that $\left\{J_{r_{n}}\right\}$ is a countable family of hemi-relatively nonexpansive mappings. Hence, $\left\{J_{r_{n}}\right\}$ is a uniformly closed countable family of hemi-relatively nonexpansive mappings.

We consider the problem of strong convergence concerning maximal monotone operators in a Banach space. Such a problem has been also studied in $[4,13,49]$. Using Theorem 11, we obtain the following result.

Theorem 27. Let $C$ be a nonempty, closed, and convex subset of a uniformly smooth and uniformly convex Banach space $E$. Let $\mathscr{A}, \mathscr{B}$ be two maximal monotone operators from $E$ to $E^{*}$ such that $\mathscr{F}=\mathscr{A}^{-1} 0 \bigcap \mathscr{B}^{-1} 0 \neq 0$, and let $\left\{r_{n}\right\}$ be a sequence of positive real numbers which is bounded away from 0 such that $J_{r_{n}}^{\mathscr{A}}=\left(I+r_{n} \mathscr{A}\right)^{-1}$ and $J_{r_{n}}^{\mathscr{B}}=\left(I+r_{n} \mathscr{B}\right)^{-1}$. For a point $x_{0} \in C$ chosen arbitrarily, let $\left\{x_{n}\right\}$ be a sequence generated by the following iterative algorithm:

$$
C_{0}=C \text {, }
$$

$$
\begin{gathered}
C_{n+1}=\left\{z \in C_{n}: \phi\left(z, J_{r_{n}}^{\mathscr{B}} y_{n}\right) \leq \phi\left(z, J_{r_{n}}^{\mathscr{A}} x_{n}\right) \leq \phi\left(z, x_{n}\right)\right\}, \\
x_{n+1}=\Pi_{C_{n+1}} x_{0},
\end{gathered}
$$

where the sequences $y_{n}=J_{r_{n}}^{\mathscr{A}} x_{n}$. Then the sequence $\left\{x_{n}\right\}$ converges strongly to a point $q=\prod_{\mathscr{F}} x_{0}$, where $\prod_{\mathscr{F}}$ is the generalized projection from $\mathrm{C}$ onto $\mathscr{F}$.

Proof. From Lemma 26, we know that $\left\{J_{r_{n}}^{\mathscr{A}}\right\}$ and $\left\{J_{r_{n}}^{\mathscr{B}}\right\}$ are two uniformly closed countable families of hemi-relatively nonexpansive mappings. Furthermore, applying Theorem 11, one sees that the sequence $\left\{x_{n}\right\}$ converges strongly to a point $\Pi_{\mathscr{F}} x_{0}$.

\section{Acknowledgments}

The authors are thankful to an anonymous referee for his useful comments on this paper. This research was supported by the Higher Education Research Promotion and National Research University Project of Thailand, Office of the Higher Education Commission under the Computational Science 
and Engineering Research Cluster (CSEC-KMUTT) (Grant Project no. NRU56000508). The first author is supported by the Project of Shandong Province Higher Educational Science and Technology Program (Grant no. J13LI51) and the Foundation of Shandong Yingcai University (Grant no. 12YCZDZR03).

\section{References}

[1] E. Blum and W. Oettli, "From optimization and variational inequalities to equilibrium problems," The Mathematics Student, vol. 63, no. 1-4, pp. 123-145, 1994.

[2] P. L. Combettes and S. A. Hirstoaga, "Equilibrium programming in Hilbert spaces," Journal of Nonlinear and Convex Analysis, vol. 6, no. 1, pp. 117-136, 2005.

[3] Z.-M. Wang, X. Qin, Z. Gu, and Y. Su, "Strong convergence theorems for a family non-expansive mappings and application to generalized mixed equilibrium problems systems," Journal of Applied Mathematics and Computing, vol. 36, no. 1-2, pp. 507519, 2011.

[4] Z.-M. Wang, M. K. Kang, and Y. J. Cho, "Convergence theorems based on the shrinking projection method for hemi-relatively nonexpansive mappings, variational inequalities and equilibrium problems," Banach Journal of Mathematical Analysis, vol. 6, no. 1, pp. 11-34, 2012.

[5] Z.-M. Wang, Y. Su, S. Y. Cho, and W. Lou, "A new iterative algorithm for equilibrium and fixed point problems of nonexpansive mapping," Journal of Global Optimization, vol. 50, no. 3, pp. 457472, 2011.

[6] S. Saewan and P. Kumam, "Modified hybrid block iterative algorithm for convex feasibility problems and generalized equilibrium problems for uniformly quasi- $\phi$-asymptotically nonexpansive mappings," Abstract and Applied Analysis, vol. 2010, Article ID 357120, 22 pages, 2010.

[7] X. Qin, Y. J. Cho, and S. M. Kang, "Convergence theorems of common elements for equilibrium problems and fixed point problems in Banach spaces," Journal of Computational and Applied Mathematics, vol. 225, no. 1, pp. 20-30, 2009.

[8] H. K. Xu, "Inequalities in Banach spaces with applications," Nonlinear Analysis. Theory, Methods \& Applications, vol. 16, no. 12, pp. 1127-1138, 1991.

[9] S. Ishikawa, "Fixed points by a new iteration method," Proceedings of the American Mathematical Society, vol. 44, pp. 147-150, 1974.

[10] W. Takahashi, Nonlinear Functional Analysis, Yokohama Publishers, Yokohama, Japan, 2000.

[11] S. Reich, "Book Review: geometry of Banach spaces, duality mappings and nonlinear problems," Bulletin of the American Mathematical Society, vol. 26, no. 2, pp. 367-370, 1992.

[12] D. Butnariu, S. Reich, and A. J. Zaslavski, "Weak convergence of orbits of nonlinear operators in reflexive Banach spaces," Numerical Functional Analysis and Optimization, vol. 24, no. 56, pp. 489-508, 2003.

[13] S.-Y. Matsushita and W. Takahashi, "A strong convergence theorem for relatively nonexpansive mappings in a Banach space," Journal of Approximation Theory, vol. 134, no. 2, pp. 257266, 2005.

[14] S. Reich, "A weak convergence theorem for the alternating method with Bregman distances," in Theory and Applications of Nonlinear Operators of Accretive and Monotone Type, A. G.
Kartsatos, Ed., vol. 178, pp. 313-318, Dekker, New York, NY, USA, 1996.

[15] Y. Su, Z. Wang, and H. Xu, "Strong convergence theorems for a common fixed point of two hemi-relatively nonexpansive mappings," Nonlinear Analysis. Theory, Methods \& Applications, vol. 71, no. 11, pp. 5616-5628, 2009.

[16] Z. Wang, Y. Su, D. Wang, and Y. Dong, "A modified Halperntype iteration algorithm for a family of hemi-relatively nonexpansive mappings and systems of equilibrium problems in Banach spaces," Journal of Computational and Applied Mathematics, vol. 235, no. 8, pp. 2364-2371, 2011.

[17] W. Takahashi and K. Zembayashi, "Strong and weak convergence theorems for equilibrium problems and relatively nonexpansive mappings in Banach spaces," Nonlinear Analysis. Theory, Methods \& Applications, vol. 70, no. 1, pp. 45-57, 2009.

[18] C. Jaiboon and P. Kumam, "A general iterative method for addressing mixed equilibrium problems and optimization problems," Nonlinear Analysis. Theory, Methods \& Applications, vol. 73, no. 5, pp. 1180-1202, 2010.

[19] K. Wattanawitoon and P. Kumam, "Strong convergence theorems by a new hybrid projection algorithm for fixed point problems and equilibrium problems of two relatively quasinonexpansive mappings," Nonlinear Analysis. Hybrid Systems, vol. 3, no. 1, pp. 11-20, 2009.

[20] K. Wattanawitoon and P. Kumam, "Corrigendum to "Strong convergence theorems by a new hybrid projection algorithm for fixed point problems and equilibrium problems of two relatively quasi-nonexpansive mappings'”' Nonlinear Analysis. Hybrid Systems, vol. 3, no. 1, pp. 11-20, 2009.

[21] P. Kumam, "A new hybrid iterative method for solution of equilibrium problems and fixed point problems for an inverse strongly monotone operator and a nonexpansive mapping," Journal of Applied Mathematics and Computing, vol. 29, no. 12, pp. 263-280, 2009.

[22] P. Kumam, "A hybrid approximation method for equilibrium and fixed point problems for a monotone mapping and a nonexpansive mapping," Nonlinear Analysis. Hybrid Systems, vol. 2, no. 4, pp. 1245-1255, 2008.

[23] P. Phuangphoo and P. Kumam, "A new hybrid projection algorithm for system of equilibrium problems and variational inequality problems and two finite families of quasi- $\phi$ nonexpansive mappings," Abstract and Applied Analysis, vol. 2012, Article ID 107296, 13 pages, 2013.

[24] P. Kumam and C. Jaiboon, "A new hybrid iterative method for mixed equilibrium problems and variational inequality problem for relaxed cocoercive mappings with application to optimization problems," Nonlinear Analysis. Hybrid Systems, vol. 3, no. 4, pp. 510-530, 2009.

[25] C. Jaiboon and P. Kumam, "A hybrid extragradient viscosity approximation method for solving equilibrium problems and fixed point problems of infinitely many nonexpansive mappings," Fixed Point Theory and Applications, vol. 2009, Article ID 374815, 32 pages, 2009.

[26] W. Kumam and P. Kumam, "Hybrid iterative scheme by a relaxed extragradient method for solutions of equilibrium problems and a general system of variational inequalities with application to optimization," Nonlinear Analysis. Hybrid Systems, vol. 3, no. 4, pp. 640-656, 2009.

[27] C. Jaiboon, W. Chantarangsi, and P. Kumam, "A convergence theorem based on a hybrid relaxed extragradient method for generalized equilibrium problems and fixed point problems of 
a finite family of nonexpansive mappings," Nonlinear Analysis. Hybrid Systems, vol. 4, no. 1, pp. 199-215, 2010.

[28] S. Saewan, P. Kumam, and K. Wattanawitoon, "Convergence theorem based on a new hybrid projection method for finding a common solution of generalized equilibrium and variational inequality problems in Banach spaces," Abstract and Applied Analysis, vol. 2010, Article ID 734126, 25 pages, 2010.

[29] N. Petrot, K. Wattanawitoon, and P. Kumam, "A hybrid projection method for generalized mixed equilibrium problems and fixed point problems in Banach spaces," Nonlinear Analysis. Hybrid Systems, vol. 4, no. 4, pp. 631-643, 2010.

[30] S. Saewan and P. Kumam, "Modified hybrid block iterative algorithm for convex feasibility problems and generalized equilibrium problems for uniformly quasi- $\phi$-asymptotically nonexpansive mappings," Abstract and Applied Analysis, vol. 2010, Article ID 357120, 22 pages, 2010.

[31] T. Jitpeera and P. Kumam, "A new hybrid algorithm for a system of mixed equilibrium problems, fixed point problems for nonexpansive semigroup, and variational inclusion problem," Fixed Point Theory and Applications, vol. 2011, Article ID 217407, 27 pages, 2011.

[32] S. Saewan and P. Kumam, "A hybrid iterative scheme for a maximal monotone operator and two countable families of relatively quasi-nonexpansive mappings for generalized mixed equilibrium and variational inequality problems," Abstract and Applied Analysis, vol. 2010, Article ID 123027, 31 pages, 2010.

[33] K. Wattanawitoon and P. Kumam, "Generalized mixed equilibrium problems for maximal monotone operators and two relatively quasi-nonexpansive mappings," Thai Journal of Mathematics, vol. 9, no. 1, pp. 171-195, 2011.

[34] T. Jitpeera, U. Witthayarat, and P. Kumam, "Hybrid algorithms of common solutions of generalized mixed equilibrium problems and the common variational inequality problems with applications," Fixed Point Theory and Applications, vol. 2011, Article ID 971479, 28 pages, 2011.

[35] P. Kumam and S. Plubtieng, "Convergence theorems by hybrid methods for monotone mappings and a countable family of nonexpansive mappings and its applications," International Journal of Pure and Applied Mathematics, vol. 70, no. 1, pp. 81107, 2011.

[36] S. Saewan and P. Kumam, "A modified hybrid projection method for solving generalized mixed equilibrium problems and fixed point problems in Banach spaces," Computers \& Mathematics with Applications, vol. 62, no. 4, pp. 1723-1735, 2011.

[37] K. Wattanawitoon, U. Humphries, and P. Kumam, "Strong convergence theorems for two relatively asymptotically nonexpansive mappings in Banach spaces," International Journal of Mathematical Analysis, vol. 5, no. 33-36, pp. 1719-1732, 2011.

[38] T. Jitpeera and P. Kumam, "A new hybrid algorithm for a system of equilibrium problems and variational inclusion," Annali dell'Universitá di Ferrara. Sezione VII, vol. 57, no. 1, pp. 89-108, 2011.

[39] W. Kumam, C. Jaiboon, P. Kumam, and A. Singta, "A shrinking projection method for generalized mixed equilibrium problems, variational inclusion problems and a finite family of quasinonexpansive mappings," Journal of Inequalities and Applications, vol. 2010, Article ID 458247, 25 pages, 2010.

[40] S. Saewan and P. Kumam, "A strong convergence theorem concerning a hybrid projection method for finding common fixed points of a countable family of relatively quasi-nonexpansive mappings," Journal of Nonlinear and Convex Analysis, vol. 13, no. 2, pp. 313-330, 2012.

[41] T. Jitpeera and P. Kumam, "Hybrid algorithms for minimization problems over the solutions of generalized mixed equilibrium and variational inclusion problems," Mathematical Problems in Engineering, vol. 2011, Article ID 648617, 25 pages, 2011.

[42] S. Saewan and P. Kumam, "A new modified block iterative algorithm for uniformly quasi- $\phi$-asymptotically nonexpansive mappings and a system of generalized mixed equilibrium problems," Fixed Point Theory and Applications, vol. 2011, article 35, 2011.

[43] P. Phuangphoo and P. Kumam, "A new hybrid projection algorithm for system of equilibrium problems and variational inequality problems and two finite families of quasi- $\phi$ nonexpansive mappings," Abstract and Applied Analysis, vol. 2013, Article ID 107296, 13 pages, 2013.

[44] S. Saewan, P. Kumam, and P. Kanjanasamranwong, "The hybrid projection algorithm for finding the common fixed points and the zeroes of maximal monotone operators in Banach spaces," Optimization, 2012.

[45] J. Kang, Y. Su, and X. Zhang, "Shrinking projection algorithm for fixed points of firmly nonexpansive mappings and its applications," Fixed Point Theory, vol. 11, no. 2, pp. 301-310, 2010.

[46] Y. Su, H.-k. Xu, and X. Zhang, "Strong convergence theorems for two countable families of weak relatively nonexpansive mappings and applications," Nonlinear Analysis. Theory, Methods \& Applications, vol. 73, no. 12, pp. 3890-3906, 2010.

[47] Y. I. Alber, "Metric and generalized projection operators in Banach spaces: properties and applications," in Theory and Applications of Nonlinear Operators of Accretive and Monotone Type, A. Kartsatos, Ed., vol. 178, pp. 15-50, Dekker, New York, NY, USA, 1996.

[48] S. Kamimura and W. Takahashi, "Strong convergence of a proximal-type algorithm in a Banach space," SIAM Journal on Optimization, vol. 13, no. 3, pp. 938-945, 2002.

[49] J. Zhang, Y. Su, and Q. Cheng, "Simple projection algorithm for a countable family of weak relatively nonex- pansive mappings and applications," Fixed Point Theory and Applications, vol. 2012, article 205, 2012.

[50] P. L. Combettes, "The convex feasibility problem in image recovery," in Advances in Imaging and Electron Physics, $\mathrm{P}$. Hawkes, Ed., vol. 95, pp. 155-270, Academic Press, New York, NY, USA, 1996.

[51] T. Kotzer, N. Cohen, and J. Shamir, "Image restoration by a novel method of parallel projection onto constraint sets," Optics Letters, vol. 20, no. 10, pp. 1172-1174, 1995.

[52] T. Kotzer, N. Cohen, and J. Shamir, "Applications of serial-and parallel-projection methods to correlation filter design," Applied Optics, vol. 34, no. 20, pp. 3883-3895, 1995.

[53] D. C. Youla and H. Webb, "Image restoration by the method of convex projectionspart-I: theory," IEEE Transactions on Medical Imaging, vol. 1, no. 2, pp. 81-94, 1982.

[54] M. I. Sezan and H. Stark, "Application of convex projection theory to image recovery in tomography and related areas," in Image Recovery: Theory and Applications, H. Stark, Ed., pp. 415462, Academic Press, Orlando, Fla, USA, 1987.

[55] Y. Censor and S. A. Zenios, Parallel Optimization: Theory, Algorithms, and Applications, Numerical Mathematics and Scientific Computation, Oxford University Press, New York, NY, USA, 1997. 
[56] A. Aleyner and S. Reich, "Block-iterative algorithms for solving convex feasibility problems in Hilbert and in Banach spaces," Journal of Mathematical Analysis and Applications, vol. 343, no. 1, pp. 427-435, 2008.

[57] J. Zhang, Y. Su, and Q. Cheng, "Strong convergence theorems for a common fixed point of two countable families of relatively quasi nonexpansive mappings and applications," Abstract and Applied Analysis, vol. 2012, Article ID 956950, 35 pages, 2012.

[58] R. T. Rockafellar, "On the maximality of sums of nonlinear monotone operators," Transactions of the American Mathematical Society, vol. 149, pp. 75-88, 1970.

[59] W. Takahashi, Convex Analysis and Approximation Fixed Points, vol. 2, Yokohama Publishers, Yokohama, Japan, 2000. 


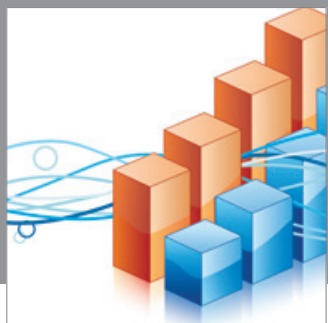

Advances in

Operations Research

mansans

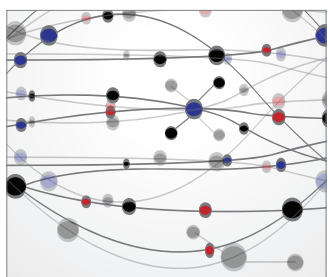

The Scientific World Journal
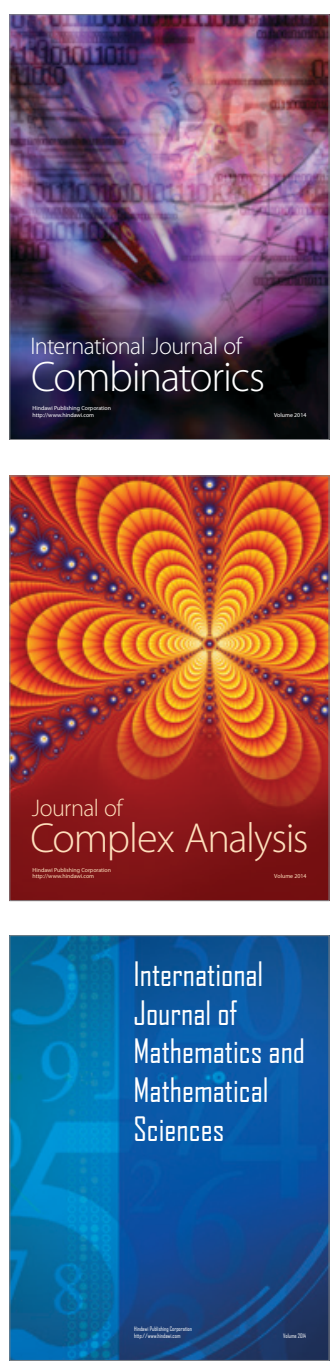
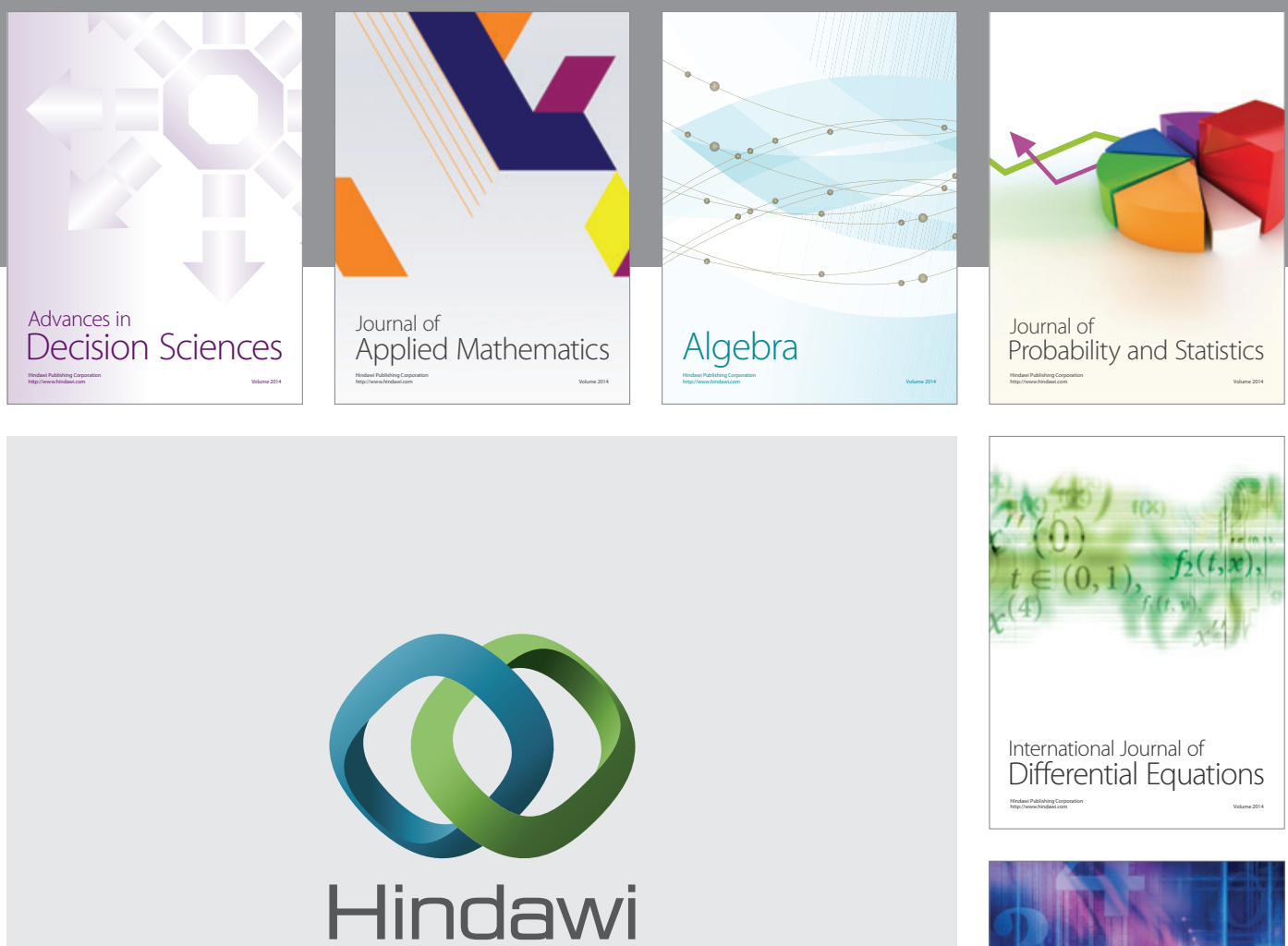

Submit your manuscripts at http://www.hindawi.com
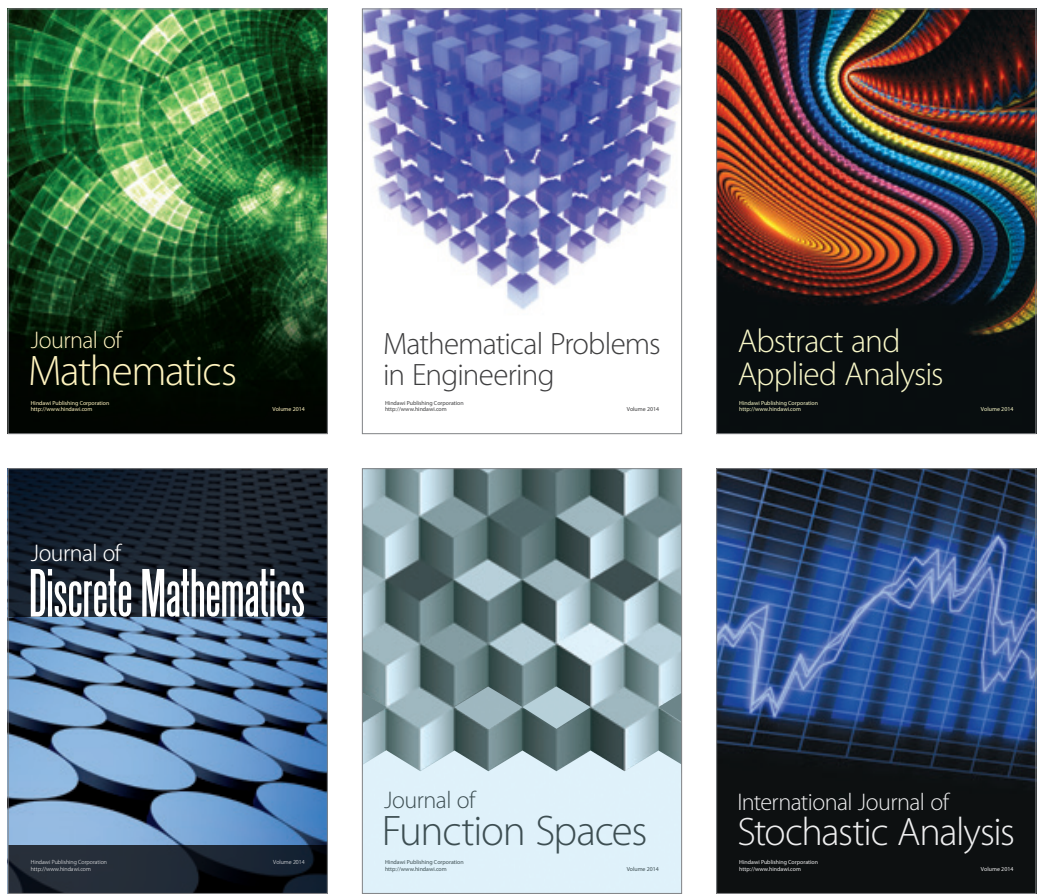

Journal of

Function Spaces

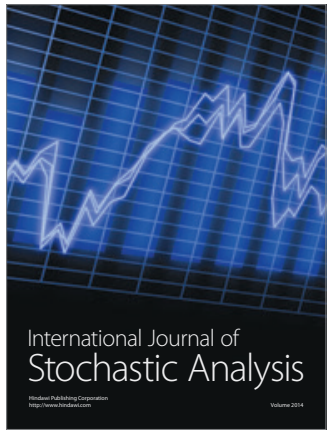

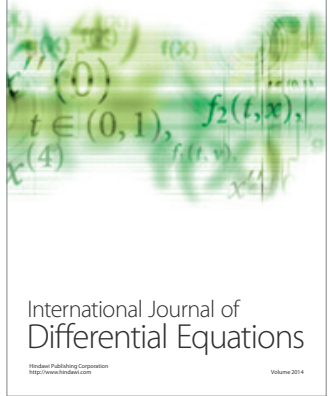
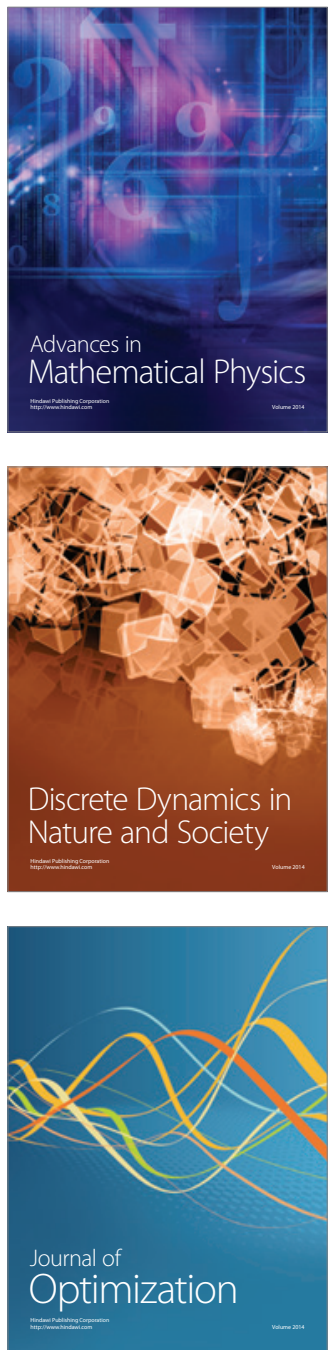